\title{
Reavaliando a etimologia de abacaxi a partir de novos dados histórico-filológicos
}

\section{Reviewing the etymology of abacaxi ('pineapple') with new historical and philological data}

\author{
Bruno Maroneze ${ }^{*}$ \\ Universidade Federal da Grande Dourados, Dourados, MS, Brasil
}

\begin{abstract}
Resumo: A hipótese etimológica consensual para abacaxi é que esta unidade lexical se origina do tupi, pela junção dos elementos yvá "fruta" e katĩ "que recende", "que exala cheiro". No presente artigo, essa hipótese é reavaliada a partir de dados de atestações anteriores desta unidade lexical. Inicialmente, apresentam-se dados lexicográficos com descrições etimológicas (seção 2); em seguida, avaliam-se as transformações fonético-fonológicas implicadas pela hipótese consensual, que levam à conclusão de que se trata de hipótese controversa (seção 3). Na seção 4, apresentam-se dados histórico-filológicos que mostram que a unidade lexical abacaxi designou um povo indígena, um rio e uma missão jesuítica, no mínimo um século antes de passar a designar uma fruta. Dessa forma, torna-se incoerente supor que uma unidade lexical que se referia a um povo pudesse ter como étimo "fruta que recende". Por fim, conclui-se que a hipótese etimológica consensual deve ser tratada como controversa e que uma nova hipótese etimológica deve ser buscada não para o nome de uma fruta, mas sim para o nome de um povo indígena.
\end{abstract}

Palavras-chave: Etimologia. Filologia. Tupinismos. Palavras de origem tupi.

Abstract: The consensual etymological hypothesis for abacaxi 'pineapple' is that this word originates from the Tupi, by the combination of the elements yvá 'fruit' and katĩ 'that smells', 'that exhalates smell'. In this article, this hypothesis is reevaluated based on data from previous attestations of this word. Initially, lexicographic data with etymological descriptions are presented (section 2); then, we evaluate the phonetic-phonological transformations implied by the consensual hypothesis, leading to the conclusion that this hypothesis it is controversial (section 3). In section 4, historical-philological data are presented that show that the word abacaxi designated an indigenous people, a river and a Jesuit mission, at least a century before designating a fruit. Thus, it is incoherent to assume that a word that referred to a people could have as its etymology 'fruit that smells'. Finally, we conclude that the consensual etymological hypothesis should be treated as controversial and that a new etymological hypothesis should be sought not for the name of a fruit, but for the name of an indigenous people.

Keywords: Etymology. Philology. Tupinisms. Words of Tupian origin.

\section{INTRODUÇÃO ${ }^{1}$}

\footnotetext{
* Professor associado, Faculdade de Comunicação, Artes e Letras, Universidade Federal da Grande Dourados, Dourados, MS, Brasil, brunomaroneze@ufgd.edu.br

${ }^{1}$ Agradeço a Andérbio Márcio Silva Martins pela ajuda com as unidades lexicais de origem indígena, e a Mário Eduardo Viaro e Eduardo Henrik Aubert pela ajuda com consultas a obras de difícil acesso.
} 
Pretende-se, neste trabalho, analisar a etimologia da unidade lexical abacaxi. Inicialmente (seção 2), são apresentados diversos dicionários da língua portuguesa que trazem informações etimológicas, todos indicando tratar-se de palavra de origem indígena (oscilando entre as denominações "tupi" e "tupi-guarani") que significa "fruta que recende", "fruta olorosa", "fruta que exala cheiro". No entanto, argumenta-se na seção 3 que essa descrição etimológica é no mínimo controversa, devido a fatores fonético-fonológicos, bem como à inexistência de dados diacrônicos que a comprovem. A partir de atestações da palavra em sincronias pretéritas ${ }^{2}$ (seção 4), argumenta-se que abacaxi foi originalmente o nome de um povo indígena da Amazônia, tendo apenas posteriormente passado a designar a fruta. Assim, nas considerações finais, conclui-se que a etimologia atualmente consensual deve ser tratada como controversa; também se apresentam algumas hipóteses etimológicas alternativas (de caráter especulativo).

\section{A ETIMOLOgIA CONSENSUAL DE ABACAXI}

A unidade lexical abacaxi, no português brasileiro contemporâneo, designa uma fruta muito conhecida e apreciada em todo o território nacional. De acordo com o dicionário Houaiss (Houaiss; Villar, 2009), o nome científico da planta é Ananas comosus. O mesmo dicionário ainda registra acepções de "trabalho complicado", "coisa ou pessoa maçante" e "português" (uso pejorativo); por fim, também informa que abacaxi é o nome de um "grupo indígena, hoje considerado extinto, que habitava o território entre os rios Tapajós e Madeira AM".

A etimologia apresentada pelo dicionário Houaiss (Houaiss; Villar, 2009) é a mesma apresentada por todos os demais dicionários consultados: do tupi *iwaka'ti (ou alguma forma semelhante, conforme será apresentado a seguir), que significaria "fruta que recende", "fruta olorosa". Por vezes, essa etimologia é marcada com um asterisco (como é o caso no dicionário Houaiss), para indicar tratar-se de uma forma reconstituída; outras vezes, a etimologia é apresentada sem indicação de forma reconstituída, como se a forma fosse atestada em tupi (ou tupi-guarani, para alguns). Essa hipótese etimológica será denominada, neste texto, de "etimologia consensual" ou "hipótese etimológica consensual".

Apresenta-se, a seguir, uma lista (não-exaustiva) de descrições etimológicas de abacaxi em dicionários gerais portugueses e em dicionários etimológicos da língua portuguesa:

\section{$2.1 \mathrm{O}$ verbete abacaxi em alguns dicionários gerais portugueses}

\section{Rubim (1853)}

O dicionário mais antigo que registra o verbete abacaxi é, de acordo com nossa pesquisa, a obra de Rubim (1853, s.v. abacachi), em que a palavra é grafada com $\mathrm{CH}$ : "ABACACHI, especie de ananaseiro; o fructo tambem conhecido com o mesmo nome, é mais delicado no sabor e aroma do que o ananaz commum." Não há informação etimológica.

\footnotetext{
${ }^{2}$ Conforme Viaro (2011), entende-se que uma sincronia pretérita é um momento da história da língua anterior ao atual.
} 


\section{Soares (1889)}

A mais antiga descrição etimológica de abacaxi que foi possível encontrar é a de Soares (1889, s.v. abacaxi). Após a descrição da fruta, inclui-se a seguinte informação: "ETYM. corr. pop. do br. ibácaxi = ibácatî fructa rescendente, de cheiro forte. Alli, $x=t x=t c h "$ ". Uma consulta à lista de abreviaturas no início da obra revela que "corr. pop." é "corrupção popular" e que "br." é a forma pela qual o dicionarista abrevia a "lingua brazil ou lingua geral tupi-guarani". Além disso, os diacríticos incluídos na descrição etimológica são também apresentados na introdução do dicionário. O símbolo $i$ refere-se ao "chamado $i$ especial do abánheenga e do

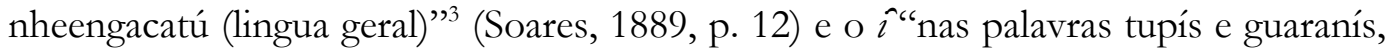
é nasal" (Soares, 1889, p. 12).

Soares não apresenta nenhuma indicação de que a etimologia seja reconstruída ou controversa; ao contrário, apresenta-a como sendo já consensual. Assim, não foi possível identificar se esse autor teve outro como referência.

\section{Freire (1957)}

O dicionário de Laudelino Freire (1957) não traz novidades em termos de informação etimológica (apresentando a mesma de Soares); porém, é o mais antigo dentre os consultados que traz a acepção do povo indígena conhecido como abacaxi, em verbete separado, flexionado no plural: “ABACAXIS, s. m. pl. Etnogr. Tribu de indígenas do Brasil, nas margens do rio Abacaxis" (Freire, 1957, s.v. abacaxis).

Houaiss; Villar (2009), Houaiss; Villar (2003) e Houaiss; Villar (s/d - online)

As três obras de Houaiss e Villar são, na verdade, variantes da mesma obra, que é o célebre dicionário conhecido como "Dicionário Houaiss". A versão de 2003, publicada em Lisboa, é mais completa do que a de 2009 (que, apesar de posterior, trata-se apenas da versão eletrônica da edição brasileira de 2001, com algumas correções). A versão de consulta online, intitulada "Grande dicionário Houaiss", é a mais completa de todas.

Em relação ao verbete abacaxi, a edição eletrônica de 2009, conforme mencionado, traz a descrição etimológica consensual, com a indicação de que se trata de forma reconstruída. A principal diferença em relação à edição de 2003 é que, na edição eletrônica, a acepção de "grupo indígena" é colocada como uma polissemia; já na edição portuguesa de 2003, há dois verbetes homonímicos: abacaxi (referente à fruta e a outras acepções relacionadas, como "trabalho complicado") e abacaxi" (referente ao grupo indígena). A descrição etimológica e a datação são apresentadas no verbete referente à fruta; nenhuma etimologia é apresentada no verbete referente ao grupo indígena. Isso parece implicar que os autores dessa obra consideraram os dois verbetes como tendo étimos diferentes.

Em relação à datação, as três versões apresentam informações importantes para identificar as primeiras datações da unidade lexical. Tanto a versão eletrônica de 2009 quanto a portuguesa de 2003 apresentam a data "a1776", mas a versão portuguesa, mais completa, identifica o texto de onde foi extraída a informação: trata-se do "Tesouro descoberto no rio Amazonas", do padre jesuíta João Daniel, escrito entre os anos de 1757 e 1776. Já a versão de consulta online, a mais completa

\footnotetext{
${ }^{3}$ Trata-se da vogal representada pelo símbolo [i] no Alfabeto Fonético Internacional.
} 
de todas, traz uma datação anterior: "c1698", com a ressalva de que é a data da acepção do povo indígena. O texto é a "Chronica da missão dos padres da Companhia de Jesus do estado do Maranhão", escrita por João Felipe Betendorf.

\section{$2.2 \mathrm{O}$ verbete abacaxi em dicionários etimológicos}

Machado (1952)

O dicionário etimológico de Machado (1952) traz a etimologia consensual: "Do tupi ibacaxi, de ibá, fruta + caxi $=$ catî, 'rescendente, cheirosa' (T.S.). Séc. XIX, Morais $^{8}$ (1890)". Não há indicação de a forma ser reconstituída. A datação mais antiga encontrada por Machado é a da oitava edição do dicionário de Morais Silva (1890).

Nascentes (1955)

O dicionário etimológico de Nascentes (1955) não registra o verbete abacaxi. No entanto, traz uma informação curiosa no verbete abacate (Nascentes, 1955, s.v. abacate):

\footnotetext{
ABACATE - Do nauatle auacate. Para o esp. aguacate a Academia Espanhola dá como étimo o mexicano abuacaquahauitl. Tastevin, Gram. da língua tupi, pg. 23, Nomes de plantas, pg. 3, lhe dá a mesma origem que abacaxi tem, alegando a permuta de $t$ e $x$.
}

A associação entre abacate e abacaxi é muito provavelmente incorreta: o abacate é uma fruta originária da região do México (e não da Amazônia, como o abacaxi), e as duas frutas são completamente diferentes em forma, sabor e cultivo. Mas a obra de Tastevin (1923), mencionada por Nascentes, apresenta dados a respeito da alternância entre $t \mathrm{e} x$, que será discutida adiante, na seção 3 .

Bueno (1968) e Bueno (1987)

Interessantemente, a obra de Bueno (1968) não traz a descrição etimológica consensual, mas sim uma anedota relacionada à acepção de "problema, dificuldade": "Abi quer dizer espinho e von Martius cita uma exclamação: abacachi! ou simplesmente abachi! como sendo o grito de dor das mulheres em sofrimento" (Bueno, 1968, s.v. abacaxi). Não nos foi possível verificar essa informação na vasta obra de von Martius; se verdadeira, talvez não seja relacionada ao nome da fruta.

Já em Bueno (1987, s.v. abacaxi), embora não se trate de um dicionário etimológico, o mesmo autor apresenta a etimologia consensual: "De Ibá, fruta; caxí, rescendente".

\section{Cunha (1982) e Cunha (1999)}

Nessas duas obras, Cunha apresenta a etimologia consensual, porém tem o cuidado de marcar com um asterisco, indicando tratar-se de forma reconstituída. A descrição etimológica em Cunha (1982, s.v. abacaxi) é: "Do tupi *ïnaka'ti (< i"ua 'fruta' + *ka'ti 'recendente')". A datação apresentada é “c1767”.

Já em Cunha (1999, s.v. abacaxi) (aqui consultada na quinta edição, mas provavelmente idealizada em data anterior à da obra de 1982), embora a descrição etimológica seja exatamente idêntica à de Cunha (1982), lê-se que 
Contrariamente ao que ocorre com o vocábulo ananás, o termo abacaxi não se documenta em nenhum dos textos de língua portuguesa dos sécs. XVI, XVII e XVIII relacionados na bibliografia.

É possível que Cunha tenha encontrado posteriormente a data de 1767, apresentada na outra obra, mas nesta, a data mais antiga é 1833, um texto em que a palavra abacaxi é uma clara referência à fruta. Contrariamente ao que afirma Cunha (1982), na seção 3 do presente artigo, apresentar-se-ão datações anteriores, no século XVII.

Pode-se perceber claramente que a etimologia apresentada pelo dicionário Houaiss foi extraída das obras de Cunha $(1982,1999)$. Também se pode perceber que o que levou o autor a usar o asterisco na descrição etimológica é a forma *ka'ti. Conforme será discutido na seção 3, a passagem de ti a xi é altamente improvável e contribui para a fragilidade dessa hipótese etimológica.

Em suma, pode-se perceber que a descrição etimológica consensual é que abacaxi deriva do tupi ibá + kati (ou alguma variante gráfica dessa forma), expressão que significa fruta que recende. Além de designar uma fruta, também designa um grupo indígena (atualmente extinto). A datação mais antiga (indicada pelo Grande Dicionário Houaiss) é a de 1698, mas não para a fruta, e sim para o grupo indígena. $\mathrm{Na}$ seção 3, a seguir, será apresentada uma contestação para essa etimologia consensual.

\section{POR QUE A ETIMOLOGIA CONSENSUAL É (PROVAVELMENTE) INCORRETA?}

A etimologia consensual de abacaxi é problemática por duas razões principais: em primeiro lugar, por razões fonético-fonológicas, que serão abordadas nesta seção; em segundo lugar, por razões histórico-filológicas, que serão abordadas na seção 4.

De acordo com a hipótese etimológica consensual, do étimo proposto $y b a^{4}+$ katĩ para a forma portuguesa abacaxi, é necessário supor três alterações fonéticofonológicas: (1) a alteração da primeira vogal [i] > [a]; (2) a fricativização [ti] > [ji]; e (3) a desnasalização [i] > [i]. O alto número de alterações fonético-fonológicas por si só já poderia levar a crer que essa hipótese é pouco provável. Além disso, também é fácil perceber que essas alterações são pouco usuais em unidades lexicais de origem tupi.

Em relação à vogal inicial, encontram-se diversas unidades lexicais portuguesas em que ocorrem as alternâncias [i] $>$ [i] e $[\mathrm{i}]>[\mathrm{u}]$. Em uvaia (nome de certa fruta), por exemplo, o étimo apresentado pelo dicionário Houaiss é ïwa + "taya (reduzido a 'aya) que seria "fruta azeda", apresentando, portanto, a alternância [i] $>$ [u]; já em jequitibá, o mesmo elemento ybá apresenta a alternância [i] $>$ [i]. Já a alternância [i] > [a] é até o momento desconhecida, a não ser em abacaxi, o que enfraquece sobremaneira a hipótese etimológica consensual.

Em relação à fricativização [ti] > [ji], esta parece ter um número relativamente alto de ocorrências em unidades lexicais de origem tupi. De acordo

\footnotetext{
${ }^{4}$ Como ocorre no guarani e em outras línguas indígenas brasileiras, a vogal [i] será aqui representada ortograficamente pela letra $y$, seguindo longa tradição iniciada já por Anchieta (1595).
} 
com o dicionário Houaiss, ocorrem as alternâncias tracutinga / tracuxinga (certa espécie de formiga) e catinga / caxinga (odor desagradável), além de iraxim (certa espécie de abelha), que proviria do tupi e'ira + tinga. Embora a maioria das palavras portuguesas em -tĩ ou -tinga desconheça qualquer alternância entre esses fonemas, Tastevin (1923, p. 23), ao descrever uma variedade da língua tupi, apresenta os pares camuti/camuxi "pote" e pituna "noite" alternando com pixuna "preto".

Além disso, há a importante evidência histórico-filológica da grafia abacatis para o povo indígena, encontrada no século XVII, conforme será apresentado na seção 4. Dessa forma, parece ser válido considerar a alternância [ti] $>[\mathrm{j} i]$ como possível.

A desnasalização do [i] final também não é inteiramente desconhecida em unidades lexicais de origem tupi: pode-se mencionar a alternância camoatim / camoati (certa espécie de vespa, conforme o dicionário Houaiss), entre outras. No entanto, esperar-se-ia encontrar, seja em textos de séculos anteriores, seja na variação linguística contemporânea, formas como *abacatim ou *abacaxim. Ainda que a ausência dessas formas não seja suficiente para invalidar a etimologia consensual, é sem dúvida um dado revelador de sua baixa probabilidade.

Assim, conclui-se que, embora não seja possível invalidar totalmente a hipótese consensual com base nos motivos fonético-fonológicos aqui apresentados, trata-se de uma hipótese de probabilidade relativamente baixa, por necessitar da postulação de três alternâncias fonéticas, duas das quais pouco frequentes em unidades lexicais de origem tupi.

Cabe ainda mencionar a possibilidade de as duas acepções principais ("fruta" $\mathrm{e}$ "povo indígena") terem étimos diferentes. Assim, abacaxi ${ }^{1}$ teria como étimo ybá + katĩ "fruta que recende" e abacaxi $i^{2}$ teria outro étimo, ainda a ser identificado. Essa possibilidade parece estar implícita na separação de homônimos apresentada em Houaiss e Villar (2003). No entanto, unidades lexicais homônimas em geral tendem a apresentar características fonético-fonológicas de alta frequência na língua, visto que, nesses casos, a probabilidade de ocorrer semelhanças por acaso é maior. Assim, formas como manga e mate, por terem poucas sílabas, serem paroxítonas e apresentarem fonemas de alta frequência na língua portuguesa, têm maior probabilidade de constituírem casos de homonímia. Não parece ser o caso de abacaxi: trata-se de palavra polissilábica e oxítona terminada em -i, características que dificilmente se apresentariam idênticas por acaso na língua portuguesa. Portanto, parece ser altamente improvável que se esteja diante de duas formas homônimas com étimos diferentes.

$\mathrm{Na}$ seção 4, a seguir, a partir de dados de sincronias pretéritas, pretende-se mostrar que a hipótese consensual deve ser abandonada.

\section{ATESTAÇÕES DE ABACAXI EM SINCRONIAS PRETÉRITAS}

A busca por datações de uma unidade lexical em sincronias pretéritas, conforme afirma Viaro (2011, pp. 106-109), faz parte do método etimológico. É preciso buscar o terminus a quo, que seria a primeira atestação de uma unidade lexical, comprovando o emprego dessa unidade em determinado período. Em relação a 
abacaxi, as primeiras atestações parecem contar uma história muito diferente da contada pela hipótese etimológica consensual.

Conforme já mencionado na seção 2.1, a versão de consulta online do dicionário Houaiss apresenta a data de 1698 para a primeira atestação de abacaxi. Trata-se do texto intitulado "Chronica da missão dos padres da Companhia de Jesus do estado do Maranhão", escrito por João Felipe Betendorf. Esse texto foi publicado em 1910 na Revista do Instituto Histórico e Geográfico Brasileiro e encontra-se disponível online (Betendorf, 1910); no entanto, como o documento tem quase 700 páginas e não está digitalizado em formato que permita buscas por palavras, não foi possível localizar o contexto maior em que abacaxi está inserido. Sabe-se apenas que se trata da acepção de "povo indígena", não a fruta.

Entretanto, é possível que se conheça uma atestação ainda mais antiga para abacaxi. Papavero e Porro (2013), comentando as localidades mencionadas pelo jesuíta Anselmo Eckart em seus escritos, apontam a existência do rio Abacaxis, às margens do qual se situa a aldeia dos Abacaxis e onde se instalou uma missão jesuítica. Os autores afirmam que o rio Abacaxis (grafado "R. de Avacachis") aparece num mapa feito pelo Pe. Samuel Fritz. S. J., em 1691, mapa este que foi reproduzido por um autor anônimo em 1810 e que pode ser encontrado na referida obra de Papavero e Porro (2013, p. 53). Em sendo verdadeira essa informação ${ }^{5}$, a primeira atestação da unidade lexical (grafada "Avacachis") passa a ser 1691.

Além dessa, outra forma ainda mais antiga pode ser encontrada: a grafia abacatis para o povo indígena, encontrada numa relação de povos indígenas apresentada pelo Pe. Simão de Vasconcellos na "Chronica da Companhia de Jesus do Estado do Brasil", datada de 1663. Nessa obra, à p. 23, na margem esquerda, encontra-se uma relação de povos indígenas encabeçada por "Nomes das nações destas gẽtes". A relação contém dezenas de nomes de povos indígenas, o penúltimo dos quais é "Abacatis". Assim, a data mais recuada, até onde as pesquisas têm apontado, parece ser 1663 .

Ao longo do século XVIII, encontra-se farta documentação que se refere tanto ao povo abacaxi quanto ao rio Abacaxis e à missão jesuítica que foi implantada para catequizá-los, também chamada por vezes de missão Abacaxi. O rio Abacaxis tem esse nome até hoje e está situado no leste do estado do Amazonas. O próprio Pe. Anselmo Eckart (em textos publicados em Papavero e Porro, 2013) menciona diversas vezes a missão Abacaxi, o que leva a crer que tenha sido um importante polo de catequização indígena na região. Essa missão também é elencada na obra de Harenberg (1760, p. 873), que contém um catálogo de missões jesuíticas pelo mundo.

Vale também mencionar que foi encontrada uma referência ao povo abacaxi com a grafia "abacate". Trata-se de um texto em espanhol, o "Diccionario Geográfico-Histórico de las Indias Occidentales o América”, de Antonio de Alcedo, datado de 1787. Nessa obra, afirma-se que o rio Erena "nace en el territorio de los Indios Abacates" (Alcedo, 1786, verbete Erena) e a descrição semelhante é feita para o rio Guia-Paraná (Alcedo, 1786, verbete Guia-Paraná). Por se tratar de um caso

\footnotetext{
${ }^{5}$ Coloca-se a dúvida porque a reprodução de 1810 do mapa pode ter sido alterada, sendo necessário verificar no mapa original, que talvez não mais exista. No entanto, há ampla documentação a respeito da existência do rio dos Abacaxis e da missão jesuítica junto ao povo abacaxi em data próxima a 1691 (ainda que posterior), o que contribui para dar suporte à data de 1691 como autêntica.
} 
isolado e em outro idioma que não o português, acredita-se que não é possível afirmar que o povo abacaxi tenha sido chamado também de "abacate".

Como se pode observar, as primeiras atestações de abacaxi são referentes a um rio, um povo e uma missão jesuítica, mas não a uma fruta. Porém, a etimologia consensual propõe que a unidade lexical significaria "fruta que recende". Assim, observa-se uma grande incompatibilidade entre a etimologia consensual de abacaxi e as suas primeiras atestações, o que é também confirmado pela ausência, nos textos da época, de qualquer referência à fruta quando se menciona o povo ou o rio. Ao contrário, o rio é que parece tomar o seu nome do povo que habita em suas redondezas.

Para esclarecer a questão, faz-se necessário também buscar as primeiras atestações de abacaxi em referência à fruta. A versão portuguesa do dicionário Houaiss (2003) indica a data de 1776, no texto intitulado "Tesouro descoberto no rio Amazonas", do Pe. João Daniel, publicado nos Anais da Biblioteca Nacional (Daniel, 1975). O trecho em que aparece a unidade lexical abacaxi (tomo 1, p. 320) é uma descrição interessantíssima e que merece ser aqui transcrita:

[...] em tanta variedade ninguém pode duvidar, que haja muita variedade de fructas deliciosas, e regaladas, das quaes apontarei algumas das mais principaes, e conhecidas, que de todas seria impossível; terá pois o primeiro lugar $\mathrm{O}^{*}$

Ananás, porque na verdade merece o primeiro lugar entre as fructas, assim pela sua grandeza, como pela sua majestosa figura, e delicioso gosto. Há várias espécies, mas duas são as mais principaes. A primeira é o ananás ordinário. A segunda chamam abacaxi: o seu feitio é como uma linda pirâmide, mas redonda tecida à maneira de pinha, e tem por coroa, e remate um galante penacho de folhas, em lugar de plumas. [...] Diferençam-se estas duas espécies em dous predicados: primeiro nas folhas. São as folhas do ananás do feitio da ũa faca de ponta larga, e adelgaçando para a ponta; ou como a folha da espadana, posto que não tão comprida como a espadana, e mais aguda, que esta para a ponta: e todas as suas folhas são do mesmo feitio, excepto, que as do ananás ordinário são lisas pelas bordas: as do ananás e abacaxis tem pelas bordas uma serrinha, que serra muito os dedos, de quem não lhe pega com jeito, e cautela, porque sempre está amolada de sua natureza, ou pela natureza. O comprimeito das folhas será um palmo, ou mais; menos as do seu penacho, ou coroa, que tem algumas mais curtas: nascem do tronco, como as da pita. A segunda diferença está no gosto; porque os ananases ordinários são muito doces, e por isso enfastiam mais depressa: não assim os abacaxis, que tem um ácido, ou acre dulce muito desenfastiado, e por isso caeteris paribus* são os mais estimados, e apetecidos. A sua planta é baixa, e cresce por modo de um craveiro, e com a mesma altura; e na haste, que sobe direita, deita por remate o seu famoso ananás, e por remate a sua coroa, ou penacho. É muito sumarento, e tão forte, que metida ũa faca em uma destas fructas, a come totalmente em pouco tempo, mas não tão brevemente, como já escreveo alguém, da noite para pela manhã, e tão bem mais o[s] abacaxis pelo seo ácido; porque todo o ácido é corrosivo do ferro.

Dessa forma, observa-se que há uma diferença de praticamente um século entre a primeira atestação de abacaxi como povo indígena e a primeira atestação como fruta. Interessantemente, o mesmo documento em que se encontra a referência à fruta também apresenta uma referência à missão jesuítica (tomo 2, p. 154): 


\begin{abstract}
[...] Um missionário que foi da missão chamada Abacaxis, e ainda vive aqui sepultado me afirmou, que em todos os anos, em que por precisão dos provimentos mandava obrigado à cidade do Pará a sua canoa, e neófitos lhes morriam aos pares quando 8 , quando 10 , quando menos 6 , e outras vezes mais [...].
\end{abstract}

Infelizmente, o autor dessas linhas não fez nenhum tipo de associação entre as duas acepções, o que poderia esclarecer o motivo pelo qual a fruta tem o mesmo nome do povo indígena e do rio. Não obstante, os dados trazidos pelas primeiras atestações indicam que a hipótese etimológica consensual é, no mínimo, controversa, não devendo ser tratada como verdadeira, conforme tratam os dicionários. As primeiras atestações da unidade lexical levam a crer que a acepção de fruta se derivou, de alguma forma, da acepção de povo indígena e/ou do nome do rio, e não o contrário.

\title{
5 CONSIDERAÇÕES FINAIS: ESPECULAÇÕES SOBRE A ETIMOLOGIA MAIS PRECISA
}

Finaliza-se esta pesquisa com duas grandes conclusões e muitas perguntas em aberto. As duas grandes conclusões a que se chega são: (1) a hipótese consensual para a etimologia de abacaxi, se não pode ainda ser inteiramente descartada, revela-se controversa e pouco provável; (2) a unidade lexical abacaxi significou primeiro um povo indígena, um rio e uma missão jesuítica, antes de passar ao significado de fruta.

Já em relação às muitas perguntas que ficam em aberto, são deixadas para pesquisas futuras:

a) Qual é a verdadeira relação entre o nome do povo indígena e o do rio? O rio se chama Abacaxis por causa do povo que habitava suas margens ou será o contrário, o povo tinha esse nome por habitar as margens do rio Abacaxis?

b) Qual é a verdadeira relação entre o nome do povo indígena, do rio e da fruta? Teriam os abacaxis domesticado a fruta? Teriam sido eles grandes cultivadores dela? Ou simplesmente habitavam um território rico em abacaxis?

c) Se abacaxi é originalmente o nome de um povo, qual seria então o significado dessa unidade lexical em alguma língua indígena? Seria o elemento abá o mesmo presente em abaetê, avá-guarani e outros, que significa "pessoa", "ser humano", "povo"? Seria abá + katĩ (pessoa que exala cheiro, pessoa fedorenta) um étimo possível?

d) Quem foi o primeiro estudioso que aventou a hipótese etimológica yvá + kati? O criador dessa hipótese teria alguma evidência documental que a fortalecesse? Ou aventou a hipótese apenas baseado em semelhanças fônicas e especulações? Se o criador foi mesmo Soares na obra de 1889, ele não apresentou nenhuma outra evidência.

Mesmo com muitas questões sem resposta, espera-se ter mostrado, com este artigo, que a etimologia de abacaxi deve ser buscada junto ao povo, hoje extinto, que certa vez habitou as margens do rio Abacaxis, no leste do estado do Amazonas, e não na fruta originária da Amazônia e hoje difundida pelo mundo todo. 


\section{REFERÊNCIAS}

Alcedo A. Diccionario Geográfico-Histórico de las Indias Occidentales o América... Tomo II. Madrid: en la imprenta de Manuel González; 1787. [citado 29 jan. 2020]. Disponível em: https://play.google.com/store/books/details?id=pCR UhdVUggC\&rdid=bookpCR UhdVUggC\&rdot=1.

Anchieta J. Arte de grammatica da lingoa mais usada na costa do Brasil. Coimbra: Antonio de Mariz, 1595. [citado 4 jul. 2020]. Disponível em: https://digital.bbm.usp.br/handle/bbm/4674.

Betendorf JF. Chronica da Missão dos Padres da Companhia de Jesus no Estado do Maranhão. Revista do Instituto Historico e Geographico Brazileiro. 1910; Tomo LXXII, Parte I. [citado 28 jan. 2020]. Disponível em: http://etnolinguistica.wdfiles.com/local--files/biblio $\% 3$ Abetendorf-1910chronica/betendorf 1910 chronica.pdf.

Bueno FS. Grande dicionário etimológico-prosódico da língua portuguesa. São Paulo: Saraiva; 1968.

Bueno FS. Vocabulário tupi-guarani português. 5. a ed. São Paulo: Brasilivros; 1987.

Cunha AG. Dicionário etimológico Nova Fronteira da língua portuguesa. Rio de Janeiro: Nova Fronteira; 1982.

Cunha AG. Dicionário histórico das palavras portuguesas de origem tupi. 5. a ed. São Paulo: Melhoramentos; Brasília: UnB; 1999.

Daniel J. Tesouro descoberto no rio Amazonas. Anais da Biblioteca Nacional. 1975; vol. 95, tomos 1 e 2, 1975. [citado 28 jan. 2020]. Disponível em: http://memoria.bn.br/pdf/402630/per402630 1975_A00095.pdf.

Freire L. Grande e novíssimo dicionário da língua portuguêsa. 3. ${ }^{a}$ ed. Rio de Janeiro: José Olympio; 1957.

Harenberg JC. Pragmatische Geschichte des Ordens der Jesuiten... Halle und Helmstädt: Carl Hermann Hemmerde; 1760. [citado 28 jan. 2020]. Disponível em: https://play.google.com/store/books/details?id=1vFiAAAAcAAJ\&rdid=book1vFiAAAAcAAJ\&rdot=1.

Houaiss A, Villar M. Dicionário Houaiss da língua portuguesa. Lisboa: Temas e Debates; 2003.

Houaiss A, Villar M. Dicionário eletrônico Houaiss da língua portuguesa. Rio de Janeiro: Objetiva; 2009.

Houaiss A., Villar M. Grande dicionário Houaiss da língua portuguesa. UOL; s/d. [citado 27 jan. 2020]. Disponível em: https://houaiss.uol.com.br/pub/apps/www/v3-3/html/index.php.

Machado JP. Dicionário etimológico da língua portuguesa. Lisboa: Confluência; 1952.

Nascentes A. Dicionário etimológico da língua portuguêsa. Rio de Janeiro: Francisco Alves; 1955.

Papavero N, Porro A. (orgs.) Anselm Eckart, S. J. e o estado do Grão-Pará e Maranhão setecentista (1785). Belém: Museu Paraense Emílio Goeldi; 2013.

Rubim BC. Vocabulario brasileiro para servir de complemento aos diccionarios da lingua portuguesa. Rio de Janeiro: Emp. Typ. Dous de Dezembro de Paula Brito; 1853. [citado 27 jan. 2020]. Disponível em: https://digital.bbm.usp.br/bitstream/bbm/3886/1/016341 COMPLETO.pdf. 
Soares AJM. Diccionario brasileiro da lingua portugueza. Rio de Janeiro: Typ. de G. Leuzinger e Filhos; 1889. [citado 27 jan. 2020]. Disponível em:

https: / / www.literaturabrasileira.ufsc.br/documentos/?action=download\&id $=76018$.

Tastevin C. Grammatica da lingua tupy. São Paulo: Officinas do Diario Oficial; 1923.

Vasconcellos S. Chronica da Companhia de Jesu do Estado do Brasil... Lisboa: na Oficina de Henrique Valente de Oliveira; 1663. [citado 29 jan. 2020]. Disponível em: https://play.google.com/store/books/details?id=bHT08G-vNSIC\&rdid=book-bHT08GvNSIC\&rdot $=1$.

Viaro M. Etimologia. São Paulo: Contexto; 2011. 